\title{
METHOD AND EQUIPMENT FOR FINAL CONCENTRATION OF THE GOLD-BEARING ALLUVIAL SANDS
}

\author{
V.N. GUBAREVICH \\ Institute "Gipromashugleobogashcheniye", 30 Pyaterkin St., \\ 348000 Lugansk, Ukraine
}

\begin{abstract}
The article describes equipment designed for final concentration of gold-bearing heavy concentrates. Final concentration is performed with a complex dry method: separation in weak and strong magnetic fields to remove metal inclusions and weakly magnetic minerals from the heavy concentrates, followed by separation of non-magnetic minerals in a magnetic fluid according to their density. This method of final concentration of the gold-bearing concentrates allows to successfully replace the amalgamation process used at present. In one application the final concentrate with the grade of $452 \mathrm{~kg} \mathrm{Au} /$ tonne, and with the recovery of $95.5 \%$ was obtain from the black sand assaying $473 \mathrm{~g} \mathrm{Au} /$ tonne.
\end{abstract}

(Received March 22, 1995, revised June 22, 1995)

\section{INTRODUCTION}

Institute "Gipromashugleobogashcheniye" designed technology and equipment for beneficiation of gold-bearing alluvial sands of placer deposits by replacing amalgamation by a special beneficiation circuit. The final concentration of gold bearing sands in a special beneficiation plant is carried out using a circuit shown in Fig. 1. The circuit consists of a vibrating hopper (1), drum magnetic separator with alternating polarity of poles (2), electromagnetic separator (3) and magnetogravimetric separator (4).

The circuit is mounted, as a module, on a metal structure (5). The final concentration of alluvial sands is carried out in a complex flowsheet: in a dry mode in weak and strong magnetic fields to remove metallic inclusions and weakly 
magnetic minerals (zircon, rutile, quartz and feldspar); and separation of non-magnetic minerals according to their density in a magnetic fluid, as is shown in Fig. 2.

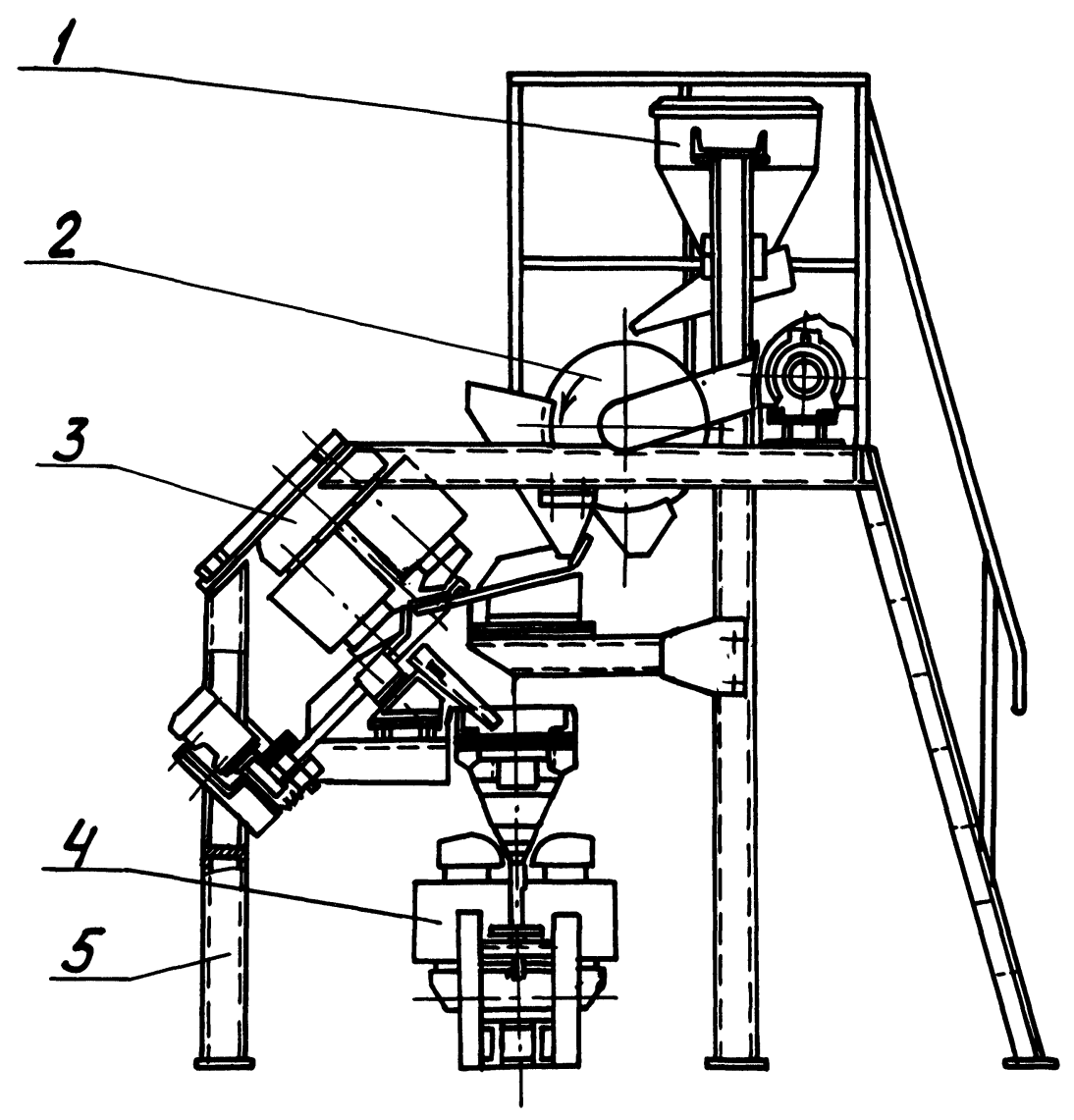

Fig. 1 Equipment for final concentration of gold-bearing alluvial sands.

(1) vibrating hopper, (2) drum magnetic separator,

(3) electromagnetic separator, (4) magnetogravimetric separator,

(5) metal structure

\section{DESCRIPTION OF THE PROCESS}

At the first stage of separation in weak magnetic field drum magnetic separator is used to recover metallic inclusions. The non-magnetic fraction is then fed in a 
magnetic separator with strong magnetic field where $25 \%$ more of weakly magnetic minerals are removed. Thus the feed in the last stage of the circuit represents approximately 20 to $25 \%$ of the demagnetised feed material.

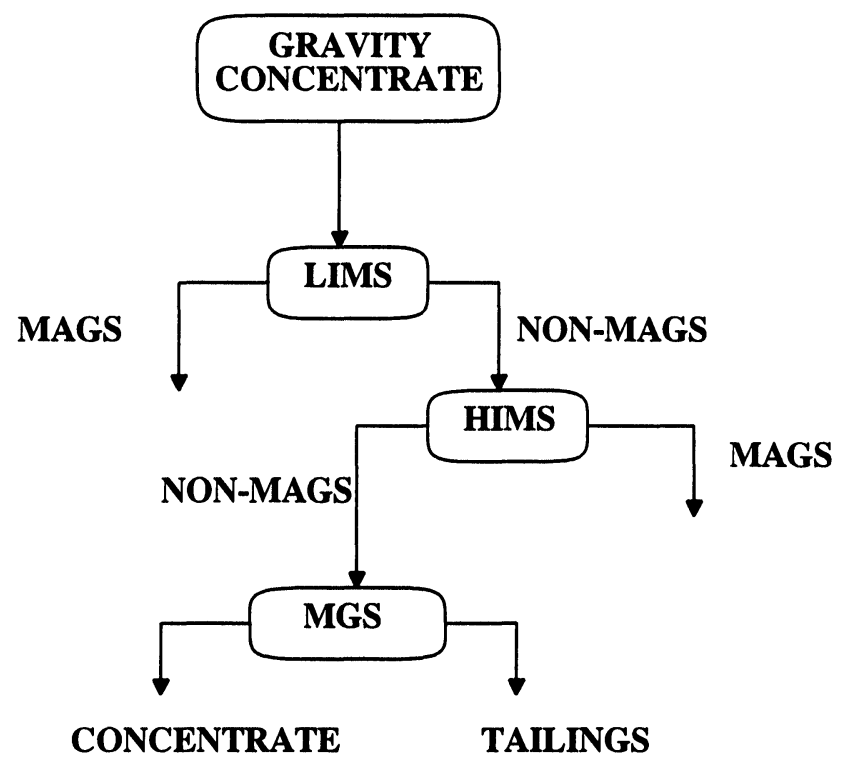

Fig. 2 Flowsheet for beneficiation of gold-bearing alluvial sands. LIMS-low-intensity magnetic separator, HIMS-high-intensity magnetic separator, MGS-magnetogravimetric separator

At the last stage separation of the non-magnetic fraction according to density is carried out in magnetic fluid of the magnetogravimetric separator shown in Fig. 3.

Magnetic fluid used in the process is based on kerosene with added finely milled magnetite. The fluid is ecologically harmless. Quantity of the magnetic fluid in the separator ranges from 2 to 5 litres and depends on the width of the inter-polar gap of the magnetogravimetric separator.

Operation of the magnetogravimetric separator is based on the unique phenomenon of increase of physical density of a magnetic fluid when placed in a 
non-homogeneous magnetic field. By changing the strength of this non-homogeneous magnetic field the apparent density of the fluid in the working space of the separator can be varied from 1.5 to $21 \mathrm{~g} / \mathrm{cm}^{3}$. Clearly, such values cannot be achieved in heavy liquids or by other methods.

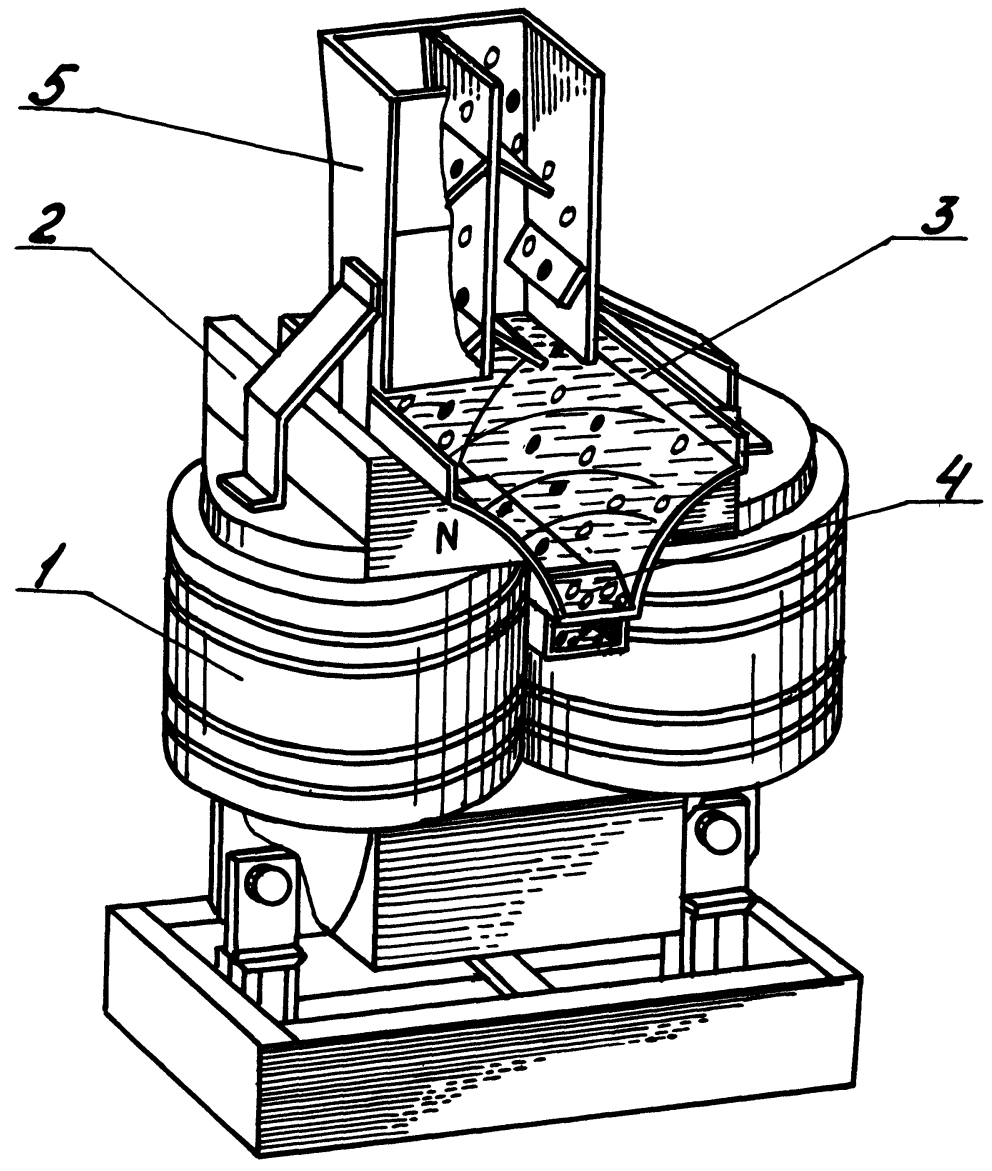

Fig. 3 Magnetogravimetric separator.

(1) magnetic system, (2) pole pieces, (3) separation vessel, (4) partition, (5) feeder 
Magnetogravimetric separator consists of a magnetic system (1) with two pole-pieces (2) shape of which determines the pattern of the magnetic field. Magnetic field varies along the height of the interpolar gap achieving maximum at the lower section of the pole-pieces and minimum in the upper part of the gap. A vessel (3) containing magnetic fluid and made from non-magnetic material is placed in the inter-polar space.

As a result of the existence of apparent density of the magnetic fluid, the feed material under the action of hydrostatic forces splits into two fractions: the light fraction, density of which is less than density in the working zone, and the heavy fraction density of which is higher than the density in the working zone.

Vessel (3) designed to separate the recovered particles from each other is equipped with a partition wall (4) in the layer of magnetic liquid. This partition wall can be moved along the vertical. The pole-pieces of the magnetic system are inclined in the direction of movement of light particles. Surface of the magnetic liquid is also inclined in this direction which allows light particles to move along the pole-pieces and to discharge from the surface of the magnetic fluid. Heavy particles density of which is higher than the apparent density of the magnetic fluid settle through the layer of the magnetic fluid into a collecting vessel.

Table I shows the results of final concentration of black alluvial sands. Overall mass yield of the magnetic fraction was $84.2 \%$, with the grade of $10.7 \mathrm{~g} \mathrm{Au}$ per tonne. The final concentrate contained $452 \mathrm{~kg}$ of gold per tonne, with the recovery of $95.5 \%$.

Table I Magnetogravimetric beneficiation of gold-bearing alluvial sands

\begin{tabular}{|c|c|c|c|}
\hline Product & Yield (\%) & Grade, $\mathrm{g} / \mathrm{t} \mathrm{Au}$ & Recovery, \%Au \\
\hline Concentrate & 0.1 & 452,000 & 95.5 \\
\hline Tailings & 15.7 & 78 & 2.6 \\
\hline Magnetics & 84.2 & 11 & 1.9 \\
\hline Feed & 100 & 473 & 100 \\
\hline
\end{tabular}


Depending on the feedrate several standard module sizes can be used for the final concentration. Specifications of these modules are summarised in Table II.

Table II Specification of equipment for the final concentration of gold-bearing alluvial sands

\begin{tabular}{|l|c|c|c|}
\hline Parameter & Module I & Module II & Module III \\
\hline Feed capacity (kg/h) & up to 20 & up to 100 & up to 600 \\
\hline Material size (mm) & $0.1-10$ & $0.1-20$ & $0.1-20$ \\
\hline Mass (tonne) & 1.5 & 2.5 & 3.5 \\
\hline $\begin{array}{l}\text { Input, motor (kW) } \\
\begin{array}{l}\text { Input, electromagnet } \\
\text { (kW) }\end{array}\end{array}$ & 1 & 2 & 3 \\
\hline $\begin{array}{l}\text { Recovery of valuable } \\
\text { component (\%) }\end{array}$ & 99 & 2 & 3 \\
\hline
\end{tabular}

\section{CONCLUSIONS}

It should be noted that the above-described technique of separation according to density can successfully replace process of amalgamation which is presently being used for final concentration of alluvial sands and of the concentrates. This method can also replace heavy toxic liquids used in beneficiation of minerals. This new method of separation is simple, reliable, highly efficient with a wide range possibilities.

Moreover, the equipment described above opens new venues for processing of domestic and industrial wastes as well as for final concentration of ores of non-ferrous and precious metals.

V.N. Gubarevich: for biography see Magn. Electr. Sep. 5 (1994), 169

Keywords: magnetogravimetric separation, magnetic fluid, gold-bearing concentrate, magnetic separation 